\title{
Prevalence and severity of self-reported asthma in young adults, 1976-2004
}

\author{
A. Browatzki*, C.S. Ulrik* and P. Lange**\#
}

\begin{abstract}
The aim of the present study was to describe the prevalence and severity of asthma in young Danish adults over three decades.
\end{abstract}

Males and females aged 20-35 yrs were sampled from the population of Copenhagen for the three surveys (1976-1978, 1991-1993 and 2001-2004). A total of 3,285 (46\% male) subjects answered a questionnaire, and had their height, weight, forced expiratory volume in 1 s (FEV 1 ) and forced vital capacity measured.

The prevalence of self-reported asthma was $1.5,4.7$ and $6.9 \%$, respectively, in the three surveys $(p<0.001)$. An increasing prevalence of asthma was observed in both males and females, although it was highest among females. The difference in FEV 1 between asthmatic and nonasthmatic subjects gradually increased, being $2.3(p=0.56)$ and $14.2 \%$ of the predicted value $(p<0.001)$, respectively, in 1976-1978 and 2001-2004. From the 1991-1994 survey, increasing body mass index, especially $>30 \mathrm{~kg} \cdot \mathrm{m}^{-2}$, was associated with a lower percentage predicted FEV 1 $(p \leqslant 0.005)$, and further analyses suggested an additive effect of asthma and obesity on FEV 1 . The proportion of smokers declined from 60 to $38 \%(p<0.001)$.

The prevalence and severity of asthma have continued to increase over the last three decades among young Danish adults, and the observed increase in severity seems, at least partly, to be related to the increase in prevalence of obesity.

KEYWORDS: Asthma, prevalence, severity, young adults

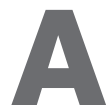
sthma is a major health problem with regard to both quality of life and morbidity, and may even be potentially life-threatening [1-3]. Several studies from a number of countries have reported an increase in the prevalence of asthma since the 1980s [4-7], and there is clear evidence that this increase cannot be ascribed to increased awareness of asthma [7]. However, very recent studies suggest that the prevalence had reached a plateau in many Western countries close to the turn of the twenty-first century $[4,7,8]$, but it is not yet known whether this plateau has been reached in all countries [4,9]. Furthermore, it is still not fully understood whether the observed changes in prevalence of asthma are related to smoking habits, other lifestyle factors or perhaps unknown environmental factors.

Several cross-sectional and longitudinal studies of adults with asthma have shown that asthmatics, on average, show reduced lung function and also a steeper decline over time compared to nonasthmatics [10-13]. However, time trends in severity of asthma have not been extensively studied [6], although this might provide important insight related to the impact of lifestyle factors and therapy on morbidity.
The Copenhagen City Heart Study comprises a large random sample of the adult general population of central Copenhagen, Denmark, that has been repeatedly examined over three decades, i.e. 1976-2004. Based on this study, the primary aim of the present analysis was to investigate the potential changes over time in prevalence and severity, as judged by lung function, of asthma in young adults aged 20$35 \mathrm{yrs}$, including the potential impact of smoking and body mass index (BMI).

\section{METHODS}

\section{Study population and procedures}

All of the subjects included in the present analysis took part in the Copenhagen City Heart Study, a prospective cardiopulmonary study initiated in 1976. Details of the selection procedure and a description of the nonresponders, together with the complete examination programme, have been published previously [14-16]. This prospective epidemiological cardiopulmonary study included a population sample drawn from the Copenhagen Population Register of $\sim 90,000$ inhabitants aged $\geqslant 20$ yrs. The sample was stratified by age, with the main emphasis on those aged 35-70 yrs. However, $\sim 5 \%$ of the population in the $20-35-y r$
AFFILIATIONS

*Dept of Cardiology and Respiratory Medicine, Hvidovre Hospital,

Hvidovre, and

${ }^{*}$ Copenhagen City Heart Study,

Bispebjerg Hospital, Copenhagen,

Denmark.

CORRESPONDENCE

C.S. Ulrik

Dept of Cardiology and Respiratory

Medicine 253

Hvidovre Hospital

DK-2650 Hvidovre

Denmark

E-mail: csulrik@dadlnet.dk

Received:

Nov 242008

Accepted after revision:

June 072009

First published online:

July 022009 
age group were also included. Furthermore, in accordance with the sampling procedure, an additional random sample of young adults, i.e. those aged 20-35 yrs, were included in each of the subsequent three surveys. To date, four surveys have been carried out, in 1976-1978, 1981-1984, 1991-1994 and 2001-2004. However, since there was a substantial overlap of participants in the 20-35-yr age group in the first and second surveys due to the short time-span between the two surveys, only data from the first, third and fourth surveys were included in the present analysis. Furthermore, since the time-span between the third and fourth surveys was only 10 yrs, a number of subjects had to be excluded from the analysis of data from the fourth survey although they fitted into the age criteria at both the third and fourth surveys. Each individual participant, therefore, only contributed data to the analysis from their first attendance.

Only subjects aged 20-35 yrs at each of the three surveys were included in the present analysis, and a total of 3,285 subjects, i.e. $1,296,1,277$, and 712 individuals, respectively, from each of the three surveys, were included.

All participants at each of the surveys had their height and weight measured and BMI $\left(\mathrm{kg} \cdot \mathrm{m}^{-2}\right)$ calculated, and subjects were classified as normal weight $(\mathrm{BMI}<25)$, overweight (BMI 25-30) or obese (BMI >30).

\section{Questionnaire}

All of the subjects were asked to fill in a self-administered questionnaire concerning symptoms, smoking status, use of medication and illnesses. All of the questionnaires were reviewed by a member of the technical staff and categorised in terms of the presence or absence of asthma, based on the response to the question in the questionnaire "Do you have asthma?" Furthermore, participants were defined as having chronic mucus hypersecretion $(\mathrm{CMH})$ if they responded yes to the question regarding whether they had been bringing up phlegm for $\geqslant 3$ months $\cdot \mathrm{yr}^{-1}$ for $\geqslant 2$ yrs consecutively.

The questionnaire used differed between the three surveys, and more detailed questions related to respiratory symptoms and therapy were only included in the 1991-1993 and the 2001-2004 surveys [14, 16]. At these surveys, the participants were classified according to their responses to the following questions: "I get short of breath when hurrying on the level or up a slight hill" (comparable to a UK Medical Research Council (MRC) dyspnoea score of 2 [17], and defined as exercise-induced shortness of breath (SOB)); "I walk slower than people of my age on the level because of breathlessness or have to stop for breath when walking at my own pace on the level (comparable to MRC score of 3 [17], and defined as SOB); "Do you now and then wake up at night due to breathlessness" (SOB at night); "Do you cough when exercising" (exercise-induced cough); "Do you cough at night" (cough at night); "Do you have wheeze" (wheeze); "Do you have wheeze triggered by exercise" (exercise-induced wheeze); "Do you take medication for asthma" (asthma medication); and "Do you have hay fever" (allergic rhinitis).

Subjects reporting daily smoking were classified as current smokers, whereas subjects describing themselves as exsmokers or nonsmokers were classified as nonsmokers.

\section{Spirometry}

During 1976-1978, forced expiratory volume in 1 s (FEV1) and forced vital capacity (FVC) were measured using an electronic spirometer (Model No 403; Monaghan, Littleton, CO, USA), which was calibrated daily with a 1-L syringe and weekly against a water-sealed Godard spirometer (Sensormedics, Bilthoven, the Netherlands). During 1991-1994 and 20012004, a dry wedge spirometer (Vitalograph, Maidenhead, UK), calibrated weekly against a 1-L syringe, was used instead, since the electronic spirometer used previously had stopped working effectively $[6,11]$.

After at least one trial blow, each subject performed three technically acceptable forced expiratory manoeuvres. At least two measurements of FEV1 and FVC differing by $<5 \%$ had to be produced in order to pass the criterion for repeatability. The highest FEV1 and FVC were used in the analyses.

The effect of age and height on FEV1 was analysed in nonsmokers without respiratory morbidity, and these analyses were performed separately for each sample and each sex [11]. Subsequently, individual predicted FEV1 were calculated based on the derived equations, whereas FEV1/FVC was reported as an absolute percentage [11]. Furthermore, the obtained measurements of FEV1 and FEV1/FVC were also compared with European reference values [18].

\section{Statistical methods}

Data were analysed using the SPSS statistical program version 12.0 (SPSS, Chicago, IL, USA). Prevalences were tested for differences between groups using a two-sided Chi-squared test, and Yates's correction for continuity was applied for all $2 \times 2$ tables analysed. The Mantel-Haenszel Chi-squared test was used to examine for linear trends in the association between age groups and respiratory morbidity. The effect of asthma (yes or no), smoking (current smoker versus nonsmoker) and BMI (normal weight, overweight or obese) on FEV1 and FEV1/FVC was analysed by multiple linear regression separately for each of the three samples. Preliminary regression analyses of the data revealed no significant differences with regard to the effect of asthma, smoking and BMI on FEV1 and FEV1/FVC between males and females, and the final model, therefore, comprises both males and females. Furthermore, interaction terms between asthma status and other independent variables, including BMI, were included in the regression model in order to test for differences in the influence of these variables on patients with and without asthma. In all analyses, p-values of $<0.05$ were considered significant.

\section{RESULTS}

\section{Response rates}

The overall response rates in the 20-35-yr age group at the three surveys included in the present analysis declined from $83.9 \%$ at the $1976-1978$ survey to $55.1 \%$ at the $2001-2004$ survey, similar to the overall response rate in the Copenhagen City Heart Study. Females responded more frequently than males at all surveys $(p<0.008)$, whereas there were no significant differences in response rates between age-stratified subgroups. The median age was 28,31 and 28 yrs, respectively, at the three surveys. 


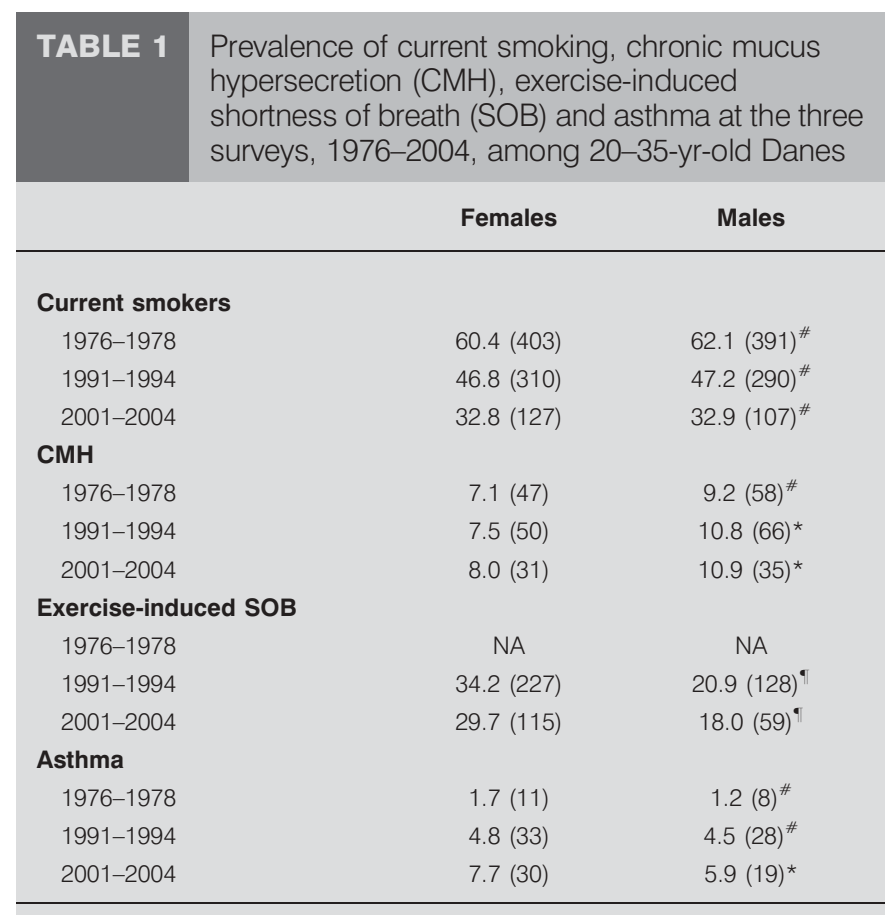

Data are presented as $\%(n)$. NA: not available. ${ }^{\#}: p=$ nonsignificant versus females; ${ }^{*}: p<0.002$; * $p<0.05$.

\section{Self-reported asthma, dyspnoea, $\mathrm{CMH}$ and smoking}

The prevalence of current smoking, $\mathrm{CMH}$, SOB on exertion and self-reported asthma by sex at the three surveys is shown in table 1 .
Asthma was reported with increasing frequency in both females $(1.7,4.8$ and $7.7 \%$, respectively; $p<0.001)$ and males $(1.2,4.5$ and $5.9 \%$, respectively; $\mathrm{p}<0.001)$ at the three surveys (table 1). Although there was a trend towards a higher prevalence of asthma in females than in males, this difference was only significant at the 2001-2004 survey $(p<0.041)$. The prevalence of self-reported asthma did not differ within 5-yr age-groups at any of the surveys.

Among the participants with self-reported asthma at the 19911994 survey, 68.3\% reported asthma symptoms triggered by allergen exposure, and, furthermore, $49.0 \%$ also reported symptoms of rhinitis in relation to allergen exposure (table 2). At the 2001-2004 survey, $>90 \%$ of the participants with selfreported asthma also reported wheeze in relation to known or unknown triggering factors, and, furthermore, $58.9 \%$ of the asthmatics reported exercise-induced wheeze; further details are given in table 2. The mean BMI was slightly higher among participants with self-reported asthma at all surveys, but this difference did not reach significance, even though the prevalence of a BMI of $>25$ was higher among asthmatics than among nonasthmatics at the two most recent surveys $(p=0.02$ and $p=0.03$, respectively) (table 2). Furthermore, the prevalence of obesity (BMI >30) more than doubled over the study period, being 4.0 and $10.3 \%$ at the first and last surveys, respectively, again with the highest prevalence among subjects with selfreported asthma (14.9 versus $9.9 \%$ at the last survey; $p=0.03$ ).

Overall, 4.0 and $2.6 \%$ of female and male participants, respectively, at the 1991-1994 survey reported daily use of asthma medication, whereas use of asthma medication was reported by 6.9 and $4.7 \%$, respectively, among females and males at the 2001-2004 survey $(\mathrm{p}=0.02)$.

\begin{tabular}{|c|c|c|c|c|c|c|}
\hline & \multicolumn{2}{|c|}{$1976-1978$} & \multicolumn{2}{|c|}{ 1991-1994 } & \multicolumn{2}{|c|}{ 2001-2004 } \\
\hline & Asthma & No asthma & Asthma & No asthma & Asthma & No asthma \\
\hline Age yrs & $26.8 \pm 4$ & $28.3 \pm 4$ & $29.7 \pm 4$ & $29.8 \pm 4$ & $28.3 \pm 5$ & $27.6 \pm 4$ \\
\hline SOB & & & $9.6(6)$ & $1.3(16)$ & $7.7(4)$ & $0.5(23)$ \\
\hline Exercise-induced SOB & & & $57.7(35)$ & $20.0(243)$ & $32.1(16)$ & $13.1(87)$ \\
\hline SOB at night & & & $46.2(28)$ & $2.5(3)$ & $23.1(11)$ & $2.2(15)$ \\
\hline Exercise-induced cough & & & $57.7(35)$ & $12.7(154)$ & $58.5(29)$ & $13.0(86)$ \\
\hline Cough at night & & & $53.8(33)$ & $12.9(157)$ & & \\
\hline $\mathrm{BMI} \mathbf{k g} \cdot \mathrm{m}^{-2}$ & $23.1 \pm 4.3$ & $22.4 \pm 3.4$ & $23.6 \pm 3.2$ & $22.6 \pm 3.5$ & $24.1 \pm 3.9$ & $23.1 \pm 3.2$ \\
\hline $\mathrm{BMI}>25 \mathrm{~kg} \cdot \mathrm{m}^{-2}$ & $13.3(3)$ & $21.0(268)$ & $41.3(25)$ & $31.0(377)$ & $43.9(22)$ & $37.7(250)$ \\
\hline FEV $1 \%$ pred & $95.2 \pm 15$ & $96.5 \pm 14$ & $86.2 \pm 15$ & $97.1 \pm 13$ & $83.1 \pm 13$ & $97.0 \pm 10$ \\
\hline $\mathrm{FEV}_{1 / \text { FVC } \%}$ & $81.2 \pm 11$ & $83.6 \pm 9$ & $78.2 \pm 10$ & $86.9 \pm 7$ & $75.9 \pm 10$ & $84.1 \pm 7$ \\
\hline
\end{tabular}

Data are presented as mean \pm SD or \% (n). CMH: chronic mucus hypersecretion; SOB: shortness of breath; BMI: body mass index; FEV1: forced expiratory volume in 1 s; $\%$ pred: \% predicted; FVC: forced vital capacity. 


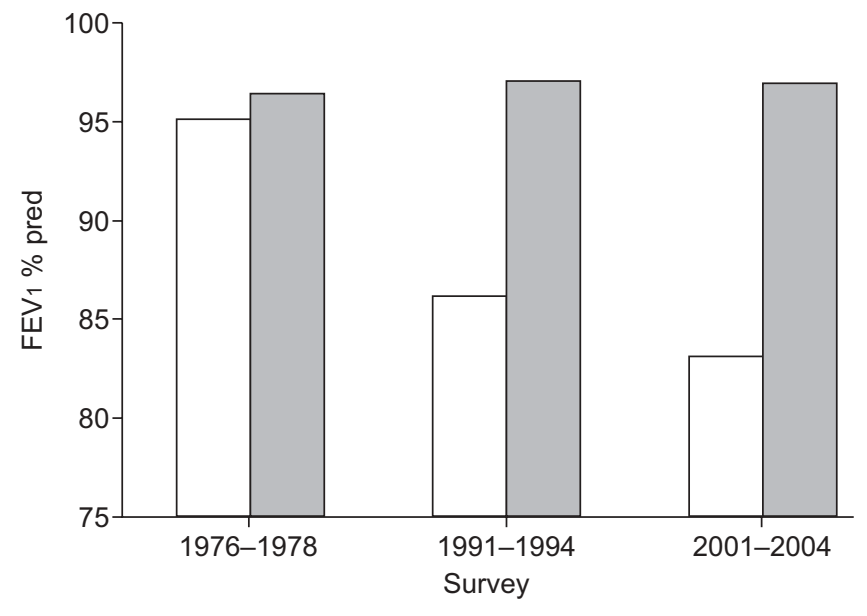

FIGURE 1. Forced expiratory volume in $1 \mathrm{~S}$ (FEV 1$)$ in asthmatics $(\square)$ and nonasthmatics ( $\square$ ) at the three surveys. \% pred: \% predicted.

At the two most recent surveys, 27.8 and $24.3 \%$, respectively, of the participants reported SOB on exertion. This symptom was reported almost twice as often by females compared to males $(\mathrm{p}=0.002)($ table 1$)$.

No significant change over time in prevalence of $\mathrm{CMH}$ was observed, but it was more prevalent among males than among females at all surveys, although significant only at the two most recent surveys $(\mathrm{p}=0.007$ and $\mathrm{p}=0.009$, respectively) (table 1). The prevalence of $\mathrm{CMH}$ was approximately three times greater among current smokers than among nonsmokers at all surveys $(\mathrm{p}<0.001)$.

The prevalence of current smokers declined over time, being $61.2,47.0$ and $32.8 \%$, respectively, at the three surveys, with no significant sex differences $(\mathrm{p}<0.001)$ (table 2$)$.

\section{Asthmatic versus nonasthmatic participants}

Over the study period, the crude difference in percentage predicted FEV1 between asthmatic and nonasthmatic subjects gradually increased (fig. 1). Subjects with self-reported asthma showed, on average, poorer lung function than nonasthmatic participants (table 2). After controlling for current smoking, the asthmatic subjects exhibited, on average, a percentage predicted FEV1 that was $14.2 \%$ lower than that of nonasthmatic participants $(p<0.001)$ at the 2001-2004 survey. This difference was, therefore, much greater than at the 1976-1978 survey, when the difference in percentage predicted FEV1 was $2.3 \% \quad(p=0.56)$ (table 3). Furthermore, at the 1976-1978 survey, BMI had no significant impact on FEV1 in participants with or without self-reported asthma. However, at the two most recent surveys, a higher BMI was significantly associated with a lower percentage predicted FEV1 ( $p=0.005$ and $p<0.001$, respectively), not least for subjects with a BMI of $>30$, in whom the FEV1 was reduced by 3.3 and $4.9 \%$ pred, respectively, compared to normal-weight participants (table 3). Furthermore, inclusion of a two-way interaction term between BMI (obese versus non-obese) and asthma status was significant for participants with self-reported asthma $(p=0.043)$, but not for nonasthmatic participants, suggesting that asthma and obesity have an additive effect on lung function. The analyses revealed, however, that obesity only partly explained the lung

\begin{tabular}{|c|c|}
\hline TABLE 3 & $\begin{array}{l}\text { sion analyses of data } \\
\text { surveys (1976-2004) of } \\
20-35-y r-o l d \text { Danes with } \\
\text { ume in } 1 \text { s (FEV1) } \\
\text { lependent variable }\end{array}$ \\
\hline Variable & Regression coefficient $(95 \% \mathrm{Cl})$ \\
\hline \multicolumn{2}{|l|}{$1976-1978$} \\
\hline Smoking & $-2.0(-3.1--0.3)$ \\
\hline \multicolumn{2}{|l|}{ BMI } \\
\hline $25-30 \mathrm{~kg} \cdot \mathrm{m}^{-2}$ & $-0.3(-1.0-0.8)$ \\
\hline$>30 \mathrm{~kg} \cdot \mathrm{m}^{-2}$ & $-0.9(-2.1-1.1)$ \\
\hline Asthma & $-2.3(-9.4-4.6)$ \\
\hline \multicolumn{2}{|l|}{ 1991-1994 } \\
\hline Smoking & $-2.9(-5.9--0.3)$ \\
\hline \multicolumn{2}{|l|}{ BMI } \\
\hline $25-30 \mathrm{~kg} \cdot \mathrm{m}^{-2}$ & $-1.4(-2.2--0.6)$ \\
\hline$>30 \mathrm{~kg} \cdot \mathrm{m}^{-2}$ & $-3.3(-5.2--1.6)$ \\
\hline Asthma & $-10.7(-13.4--7.9)$ \\
\hline \multicolumn{2}{|l|}{ 2001-2004 } \\
\hline Smoking & $-4.6(-5.8--3.4)$ \\
\hline \multicolumn{2}{|l|}{ BMI } \\
\hline $25-30 \mathrm{~kg} \cdot \mathrm{m}^{-2}$ & $-1.5(-2.9--0.3)$ \\
\hline$>30 \mathrm{~kg} \cdot \mathrm{m}^{-2}$ & $-4.9(-6.1--3.8)$ \\
\hline Asthma & $-14.2(-16.5--12.1)$ \\
\hline
\end{tabular}

Data are presented in the units of the dependent variable ( $F E V_{1} \%$ pred). Smoking and asthma status were included in the model as dichotomous variables (with nonsmoker and no asthma as reference), whereas body mass index (BMI) was included in the model in three categories, i.e. $\mathrm{BMI}>25$, BMI $25-30$ and $\mathrm{BMI}>30$ (with $\mathrm{BMl}<25$ as reference)

function deficit observed among participants with self-reported asthma.

Analysis of data for FEV1/FVC (as an absolute percentage) obtained at the three surveys revealed a similar trend, as the difference between the asthmatic and nonasthmatic participants increased from $1.9 \%$ at the $1976-1978$ survey to $8.2 \%$ at the 2001-2004 survey $(\mathrm{p}<0.001)$.

\section{DISCUSSION}

The present study shows a continuing increase in prevalence of asthma among young Danish adults during the time period 1976-2004. Furthermore, based on the spirometric data, the severity of asthma has also increased, which appears to be partly related to increasing BMI, and particularly to obesity (BMI >30). As the proportion of smokers declined from $\sim 60$ to $\sim 30 \%$ over the study period, it is unlikely that the increase in prevalence and severity of asthma is caused by an increase in smoking-related respiratory symptoms.

The observed changes in prevalence of $\mathrm{CMH}$ and dyspnoea on exertion throughout the study period were found to be nonsignificant, whereas the self-reported asthma prevalence data and spirometric data revealed not only an increase in prevalence but also, more interestingly, an increase in the impact of asthma on FEV1. We, therefore, observed a surprising dissociation between, on the one hand, the 
prevalence and severity of asthma and, on the other, more nonspecific respiratory symptoms. It has previously been shown that asthma symptoms are more prevalent among overweight subjects [19], and, furthermore, also that achievement of good asthma control is, despite adequate treatment, less likely in overweight patients than in normal-weight patients [20]. Our study revealed a change over time in the impact of BMI on lung function, and, furthermore, may suggest that, in subjects with self-reported asthma, there is an interaction between BMI and asthma status not found in subjects not reporting symptoms of asthma. Apart from suboptimal asthma control due to compliance-related issues $[21,22]$, it is, therefore, likely that the observed increase in severity of asthma, as judged by FEV1, may be due to an increasing trend towards being overweight and obese, not least among subjects with self-reported asthma. The present study, however, did not reveal major clues towards understanding the mechanisms underlying the changes over time in prevalence of self-reported asthma.

Our study confirmed previous observations that $\mathrm{CMH}$ in young adults without symptoms suggesting a diagnosis of asthma is closely associated with smoking [23]. The present study, however, also revealed a four times higher prevalence of $\mathrm{CMH}$ among asthmatics than among nonasthmatics, which could not be ascribed to smoking. The presence of $\mathrm{CMH}$ in these young adults is, therefore, likely to reflect suboptimal asthma control, i.e. uncontrolled airway inflammation.

Despite the availability of safe and effective therapy for asthma, a large proportion of asthmatics remain poorly controlled [1, 22]. One of the main reasons is poor compliance with controller medication, i.e. inhaled corticosteroids. In the present study, the proportion of subjects reporting daily use of asthma medication was substantially lower than the prevalence of self-reported asthma. It, therefore, remains a possibility that at least part of the lung function deficit observed among asthmatics is due to underuse of inhaled corticosteroids. However, the present study period represents a period in which there was a very steep increase in the prescription rate for inhaled corticosteroids in Denmark, not least among individuals aged $<40$ yrs. Consequently, we had expected a normalisation of both FEV1 and FEV1/FVC among the asthmatics, rather than the surprising finding of an increasing lung function deficit in this group.

The use of self-reported asthma, as opposed to a diagnosis supported by objective measurements, may lead to inclusion of subjects with nonasthmatic respiratory symptoms, including symptoms due to smoking [24]. However, the inclusion of only adults aged $<35$ yrs in the present analyses makes it unlikely that a substantial number of patients with chronic obstructive pulmonary disease have been misclassified as asthmatics, and, furthermore, such potential misclassification is unlikely to have changed substantially over time as the analyses did not reveal a time trend in respiratory symptoms and smoking habits. This is further supported by the observation of a high prevalence of asthma-related features, including rhinitis and wheeze triggered by allergen exposure, among participants classified as having asthma. However, we cannot exclude the possibility that asthma-like symptoms due to, for example, poor physical fitness or obesity may have been reported as asthma in a smaller number of cases.
The prevalence of self-reported asthma, which, in a substantial proportion of cases, most probably reflects doctor-diagnosed asthma, may change over a 30-yr period solely due to changes in public and/or clinical understanding of asthma [4, 25]. Interpretation of the present observations with regard to asthma prevalence should, therefore, take into account that it seems unlikely that there has been no change whatsoever over the study period in the general understanding of asthma. However, the validity of the present observations is strongly supported by the fact that the difference in lung function was greatest in the most recent survey, indicating that our findings are not due to a greater awareness of asthma or tendency to diagnose milder cases of asthma.

The present study has a number of limitations. Firstly, one limitation is the declining response rate, although it most probably represents current trends in willingness to participate in epidemiological studies [26]. Register-based follow-up of the nonresponders in the Copenhagen City Heart Study shows a higher age-adjusted mortality and morbidity than in responders. A visit was planned to a sample of the nonresponders at the end of the 1976-1978 survey, but only $30 \%$ of this sample was successfully contacted. However, these subjects showed a slightly higher prevalence of asthma and $\mathrm{CMH}$ than did responders. The true prevalence of asthma might, therefore, be higher than we have observed in this study. In addition, we have no indications that the proportion of subjects with asthma among nonresponders have changed over time. Second, the questionnaires differed between surveys, as they represented a balance between current new knowledge, the desire to obtain valuable information and acceptability for the participants. Furthermore, the participants' responses to identical questions may also change over time due to current beliefs, etc. In the present study, this seems likely to explain the observed changes in prevalence of exercise-induced SOB and exerciseinduced wheeze (table 2).

In conclusion, the present study has revealed a continuing increase in prevalence and severity of asthma among young Danish adults over the last three decades, with the latter appearing to be related to, but not fully explained by, changes in BMI.

\section{STATEMENT OF INTEREST}

None declared.

\section{REFERENCES}

1 Rabe KF, Adachi M, Lai CK, et al. Worldwide severity and control of asthma: the global asthma insights and reality surveys. J Allergy Clin Immunol 2004; 114: 40-47.

2 Global Initiative for Asthma. Global Strategy for Asthma Management and Prevention. NHLBI/WHO Workshop Report. Update of NIH Publication No. 95:3659. www.ginasthma.com/ Guidelineitem.asp??11 =2\&12=1\&intId=1561 Date last updated: December 2008. Date last accessed: August 19, 2009.

3 National Asthma Education and Prevention Program. Expert Panel: Guidelines for the Diagnosis and Management of Asthma. www. nhlbi.nih.gov/health/public/lung/index.htm Date last updated: August 2007. Date last accessed: August 19, 2009.

4 Eder W, Ege MJ, von Mutius E. The asthma epidemic. N Engl J Med 2006; 355: 2226-2235. 
5 Brögger J, Bakke P, Eide GE, et al. Long-term changes in adult asthma prevalence. Eur Respir J 2003; 21: 468-472.

6 Hansen EF, Rappeport Y, Vestbo J, et al. Increase in prevalence and severity of asthma in young adults in Copenhagen. Thorax 2000; 55: 833-836.

7 Martinez FD. Trends in asthma prevalence, admission rates, and asthma deaths. Respir Care 2008; 53: 561-567.

8 Braun-Fahrländer $\mathrm{CH}$, Gassner M. No further increase in asthma, hay fever and atopic sensitization in adolescents living in Switzerland. Eur Respir J 2004; 23: 407-413.

9 Nowak D, Ulrik CS, von Mutius E. Asthma and atopy: has peak prevalence been reached? Eur Respir J 2004; 23: 359-360.

10 Peat JK, Woolcock AJ, Cullen K. Rate of decline of lung function in subjects with asthma. Eur J Respir Dis 1987; 70: 171-179.

11 Lange P, Parner J, Vestbo J, et al. A 15-year follow-up study of ventilatory function in adults with asthma. N Engl J Med 1998; 339: 1194-1200.

12 Ulrik CS, Lange P. Decline of lung function in adults with bronchial asthma. Am J Respir Crit Care Med 1994; 150: 629-634.

13 Sears MR. Lung function decline in asthma. Eur Respir J 2007; 30: 411-413.

14 The Copenhagen City Heart Study. Østerbroundersøgelsen. A book of tables with data from the first examination (1976-78) and a five year follow-up (1981-83). Scand J Soc Med Suppl 1989; 41: 1-160.

15 Epidemiology of chest pain and angina pectoris, with special reference to treatment needs. Acta Med Scand Suppl 1984; 682: 1-120.

16 Schnohr P, Jensen GB, Lange P, et al. The Copenhagen City Heart Study. Tables with data from the third examination 1991-4. Eur Heart J 2001; 3: Suppl. H, 1-54.
17 Fletcher CM. Standardised questionnaire on respiratory symptoms: a statement prepared and approved by the MRC Committee on the Aetiology of Chronic Bronchitis (MRC breathlessness score). BMJ 1960; 2: 1665.

18 Roca J, Burgos F, Sunyer J, et al. Reference values for forced spirometry. Eur Respir J 1998; 11: 1354-1362.

19 Weiss ST. Obesity: insight into the origins of asthma. Nat Immunol 2005; 6: 537-539.

20 Boulet IP, Franssen E. Influence of obesity on response to fluticasone with or without salmeterol in moderate asthma. Respir Med 2007; 101: 2240-2247.

21 Partridge MR. Asthma 1987-2007. What have we achieved and what are the persisting challenges? Prim Care Respir J 2007; 16: 145-148.

22 Ulrik CS, Backer V, Søes-Petersen U, et al. The patient's perspective: adherence or non-adherence to asthma controller therapy? J Asthma 2006; 43: 701-704.

23 Ulrik CS, von Linstow ML, Nepper-Christensen S, et al. Chronic mucus hypersecretion: a marker of asthma in young adults? Respir Med 2005; 99: 1576-1582.

24 Yunesian M, Hormayour-Vagh J, Asghani F, et al. Smoking-related respiratory symptoms in Tehran: a cross sectional study. Arch Iran Med 2008; 11: 507-514.

25 Jackson M. Asthma, illness and identity. Lancet 2008; 372: 10301031.

26 Bjørkelund C, Andersson-Hange D, Andersson K, et al. Secular trends in cardiovascular risk factors with a 36-year perspective: observations from 38- and 50-year olds in the Population Study of Women in Gothenburg. Scand J Prim Health Care 2008; 26: 140-146. 